\title{
DEVELOPMENT OF AUTOMATIC ROAD MARKING REMOVING EQUIPMENT USING HIGH PRESSURE WATER-JET
}

\author{
Kyung-Min Park*, Young-Bog Ham*, Soon-Wook Kwon**, Kyoon-Tai Kim**, Jae-Goo \\ Han**, Jeoung-Tae Kim*** \\ * Advanced Industrial Technology Department, Korea Institute of Machinery \& Materials,
Yusung-Gu, Daejeon, Republic of Korea (zip code: 305-343), (e-mail: hyb665@ kimm.re.kr )
}

** Construction Engineering \& Management Research Department, Korea Institute of Construction Technology, Goyang-Si, Gyeonggi-Do, Republic of Korea (zip code: 411-712), (e-mail: swkwon@kict.re.kr )

*** Advanced Motion Technology Co., Ltd, Paju-Si, Gyeonggi-Do, Republic of Korea, (zip code: 413-835), (e-mail: amotion1 @ kornet.net )

\begin{abstract}
Present removal work for road markings has been time-consuming and labor intensive because it has been performed manually using shaving type equipment. The traditional process causes traffic delay due to the passing control, resulting in unexpected accidents to workers working at dangerous road circumstance. Besides, the current shaving method leads to air pollution as well as explosive accidents caused by propane gas. Thus, we have studied to develop the automatic removing equipment which consists of a high pressure water-jet system, automatic control system and mobile system: the water-jet system consists of an intensifier and nozzles to give a high pressure and spray on the marking; the automatic control system is composed of one axis robot using a hydraulic servo actuator controlled by a lever; and the mobile system employs a truck which plays an important role for transport of equipment and forward movement in a removal process. In this paper, we have analyzed the characteristics of road markings and investigated current removing methods in this field. In addition, we have organized and designed automatic removing equipment. We have also made a basic experiment to find out the optimized spray condition such as spray distance, spray angle and injection pressure.
\end{abstract}

Keywords : work process analysis, water-jet system, road marking, intensifier, lever system,

\section{Introduction}

\subsection{Background and objective of the study}

To fulfill the original function as a road, a road must be managed and maintained in a safe, comfortable and convenient manner. In this regard, the removing work of road markings shall be performed efficiently as one of the methods to maintain the road. However, current removing processes require many workers and much time, employing a traditional manual machine such as a shaving type machine. From a social and economic point of view, these kinds of manual tasks bring about social inconvenience and economic loss including traffic jam and unanticipated costs. Moreover, from a safety perspective, manual tasks trigger various dangers such as unexpected traffic accidents or exploration of propane gas used for ground finishing, leading to health problem and environment pollution dusts and noxious gases. Accordingly, we feel keenly the necessity for the development of new alternative equipment.

The water-jet system, which already has been developed in 1960, means a machine spraying water compressed ultra-high pressure. This water-jet system is widely utilized for cutting and surface cleaning for basic materials. The innovative application of water-jet technology is expanded to such fields as electronics, mobile, machinery, construction and shipment with automated processes, easy-to-operation and manufacturing precision. The most significant advantage of this water-jet system includes low dust scattering, good working conditions and convenient automation for various applications.

Therefore, as a preliminary study for development of an automatic road marking removing equipment, this paper is designed to find out optimized spray condition including spray distance, spray angle and injection pressure by analyzing components and considerations of the equipment.

\subsection{Methods of the study}

In this paper, the following methods are used:

First, analyze current technical development both home and abroad.

Second, investigate the characteristics of various road 
markings, especially marking standards such as length, width and paints from Standard Specifications of Korea Highway Corporation.

Third, analyze current removing processes through on-site investigation.

Fourth, find out considerations and major components of developing the equipment based on the above results.

Lastly, define appropriate conditions of performance for reliable equipment design.

\subsection{Tendency of related technologies}

Since domestic reference sites of developing water jet system-based removing road marking are hardly found, current trends of related technologies focus on foreign equipment developed by SUGINO Co., Ltd (Japan) and Jetedge Co., Ltd. (America).

The system developed by SUGINO Co., Ltd (Japan)[1] consists of independent five big units such as ultra high pressure pump unit, vacuum unit, water tank unit, hydraulic unit and removal machine. The characteristic of this equipment is to circulate water by filtering clearly using vacuum and disposal units. Despite these advantages, however, there are some difficulties of setting up the whole system and moving them in other places. Above all, it is noted to employ the environment-friendly water disposal method.

The highway stripe removal system developed by Jetedge Co., Ltd. (USA)[2] is the one most similar to our new equipment in the concept of loading whole units on a truck. However, it is difficult to apply this big removal system to our narrow road conditions, along with environment unfriendly structure.

\section{Analysis of Major Components for Developing Equipment}

\subsection{Present conditions of road markings}

We have investigated the Korea Road Traffic Act[3] and Standard Specifications of Korea Highway Corporation[4] to find out the standard and various road markings on the domestic highway.

The analysis shows that road markings have a variety of types, colors and sizes. Because our main target of removing is a general traffic lane, the width of lane is an important factor. The width of lane is generally about $15 \mathrm{~cm}$ or a maximum of $20 \mathrm{~cm}$ for central lines. As a result, $20 \mathrm{~cm}$ is set to be a removable width, with extra width applied to the design.

Through a real field investigation, we analyzed other considerable conditions such as narrow working space, various road facilities and uneven ground conditions.

According to Korean Standards, three types of paints: hot spray type, hot melt type and water resoluble type are used as traffic paints. In this study, only hot melt type of paint is considered as a removing target for more effective analysis.

\subsection{On-site analysis}

For development of the new equipment, first of all, it is important to observe current work methods or processes in detail. By comparing current works with new processes, we can analyze productivity, quality, and improvement of road marking removing works if the development equipment is applied at a same field.

As shown in Figure.1, we have visited the work place to analyze problems occurred from the traditional road marking removing equipment. Also, we could set up the current working process of road marking removing.

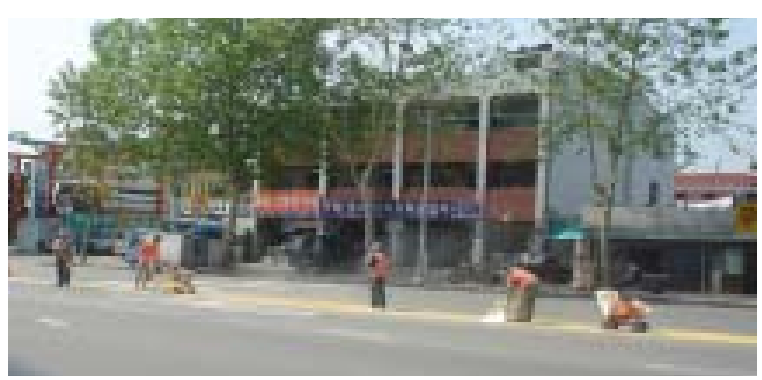

Figure 1. Working field for road marking removing

The whole working process of current road marking removing is classified into three steps: the equipment check as preparation for the work; the repetition of removing work; and working field arrangement. As the second step, the actual removing process is broken down into six steps: setting of a safety panel; marking removing using shaving type equipment; road cleaning; heating by propane gas; ground finishing for removing traces; and movement for other place. Besides, these six processes are performed repeatedly, if necessary (Figure 2).

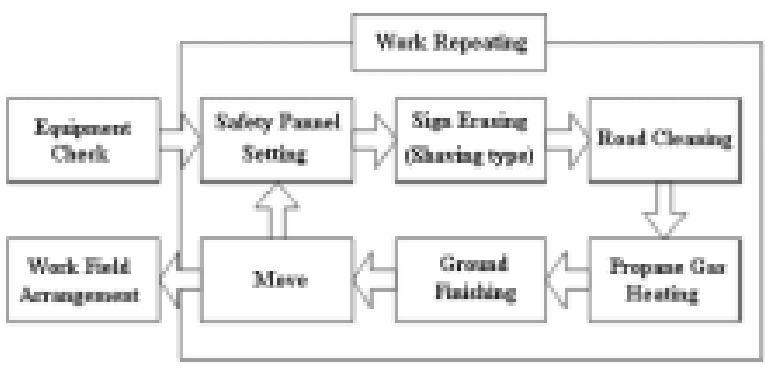

Figure 2. Diagram of the whole working process

The results of the field investigation and interviews with workers show that:

First, shaving type equipment has broken down an average of 2 3 times a day. In particular, hot summer weather causes asphalt melting and lumping, leading 
to mechanical problem in shaving lumped asphalt such as overload. Second, a variety of dangerous factors caused traffic accidents and gas explosions. Third, when the equipment shaves road markings and asphalts together, a lot of dusts and noises with high decibel occur.

\subsection{Analysis of main components}

The analysis of various characteristics on road markings and removing methods enables us to obtain more efficient equipment to overcome the disadvantages of the current system. The new equipment removes markings not by manual shaving methods but by automatic spraying methods using ultra-high pressure water without damaging road surfaces.

The innovative equipment consists of a water-jet system including a nozzle for forming ultrahigh pressure water and for spraying water on the road; an single axis manipulator system for moving the nozzle in $\mathrm{x}$ axis direction; a remote control lever system for controlling and operating equipment as a user's interface; a water tank for transporting and storing water; and a mobile system for loading this devices and moving the nozzle in $\mathrm{y}$ axis direction (Figure 3).

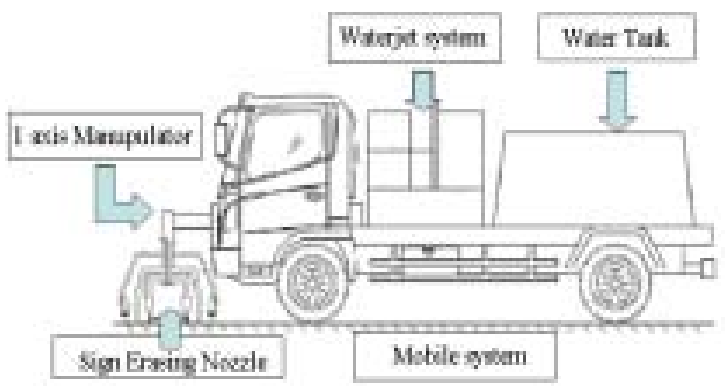

Figure 3. Concept map of the new equipment

\section{Basic Design for Components}

To design each component such as waterjet system, one axis manipulator system and control lever system, we have studied on various conditions, specifications and design standard for reliable operation

\subsection{Water-jet system}

In the design of high pressure water pump, first of all, the most important factor is maximum injection pressure. To obtain a satisfactory result in removing markings against unexpected road condition like unsmooth surface, type of paints, and double-paint, etc., we have designed water pump to inject water in the pressure of maximum 3,000 bar. To find the optimum conditions to remove markings, we would directly regulate the pressure of the water jet system in the field.
Water-jet system means that the device to use the concentrated power by injecting the water compressed with ultra-high pressure (1000 bar or higher) through the nozzle to convert potential energy into kinetic energy at sonic speed. Figure 4 shows the circuit diagram of water-jet system for removing road markings.

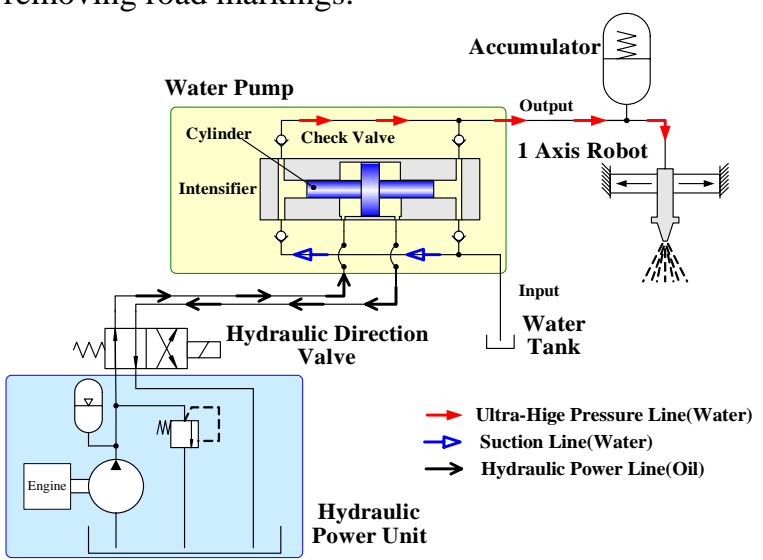

Figure 4. Water-jet system

Water-jet system (figure 5) is configured with hydraulic power unit, hydraulic valve, water pump, accumulator and nozzle. Hydraulic power unit driven by the engine functions from the driving source of water pump, that is, makes the piston in the cylinder reciprocate. Water pump is consisted of check valves to control the direction of the flow in inlet or outlet, and an intensifier to compress the water in ultra high pressure by the area ratio between piston and rod, what is called, Pascal's principle [5]. According to piston reciprocation by the action of hydraulic power unit, the water sucked from the water tank has been compressed in higher pressure. A nozzle connected with one axis manipulator sprays ultra high pressure water on the road markings. Also, the nozzle can be changed with 1-hole, 2-hole or other type. Accumulator will reduce the pulsation of pressure in outlet line.

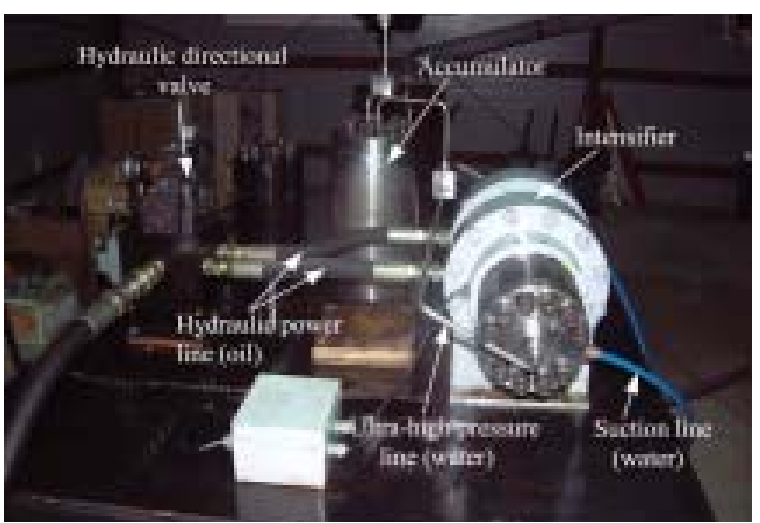

Figure 5 Configuration of water-jet system

\subsection{One Axis manipulator}

One axis manipulator system means 
hydraulic servo actuator or cylinder [6] with a positional control sensor, Linear Variable Differential Transformer (LVDT), and can transmit input and output data by an industrial computer. This system is driven by the supply flow volume which is in proportion to the electric signal put from a hydraulic servo valve, and can be controlled with precision or accuracy. The target specifications of this system is the operating speed of maximum $400 \mathrm{~mm} / \mathrm{sec}$, the repeat accuracy of less than $0.1 \mathrm{~mm}$ and precision control with the load of $20 \mathrm{kgf}$.

Figure 6 shows the control flow of one axis manipulator system.

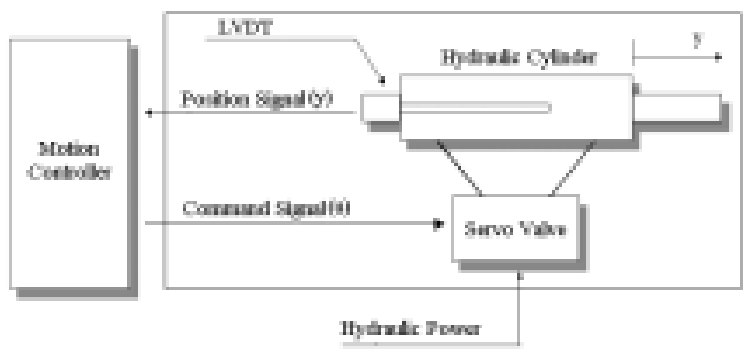

Figure 6. Concept of one axis manipulator

\subsection{Control lever system}

A control lever system is required to allow an operator to move the injection nozzle to the position he wants by simple lever operation in association with one axis manipulator. This lever system will be available by controlling one axis manipulator or hydraulic servo valve, an element which determines the direction of hydraulic servo actuator. The range of lever manipulation should be proportional to the magnitude of electric signal fed to the servo valve.

An axis lever is consisted of potentiometer, select switch, release switch, and trigger switch. Since the analog output signal generated by operating a lever and current drive unit communicate with PLC control program and electric unit in the controller, and is transferred to the servo valve, an actuator controller, to control the servo actuator or injection nozzle to desired position. Also, the displacement and velocity of a servo actuator will be measured by sensors, then the values will be converted into signal by the F/V converter and signal conditioner, and will be utilized as feedback to compensate the error.

Figure 7 shows the control algorithms of a lever system

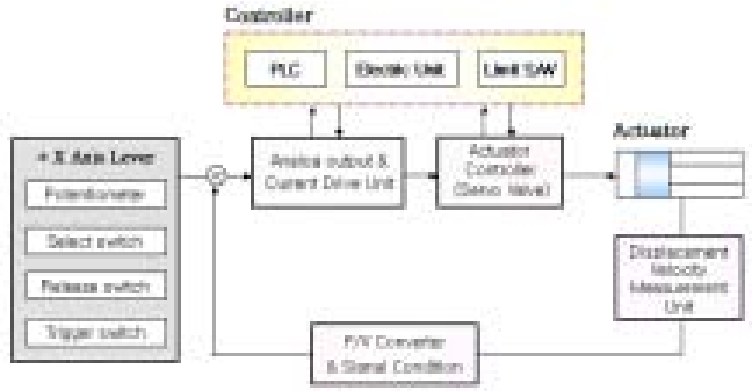

Figure 7. Algorithms of a lever system

\section{Experiment for Optimal Spray Condition}

\subsection{The Objective of the experiment}

The objective of this experiment is to examine the basic performance of manufactured equipment as well as to obtain basic data for the optimal spray condition, such as the spray distance, spray angle and injection pressure, to remove the road markings without damage before applied to the work in the field.

\subsection{Experimental method and result}

The total experiment accomplished under the atmospheric pressure and normal temperature with a 1-hole nozzle of $0.2 \mathrm{~mm}$ diameter. The specimen was manufactured in the size of $30 \mathrm{~cm} \times 30 \mathrm{~cm}$, applied the paint in thickness of $2 \mathrm{~mm}$ after dilution depending on the respective specs and dried for one week or more.

Table 1 shows parameters and conditions for the experiment.

Table 1. Experimental condition

\begin{tabular}{|c|c|}
\hline Parameter & Conditions \\
\hline Spray distance & $\begin{array}{c}10,20,30,40,50,60, \\
70,80 \mathrm{~mm}\end{array}$ \\
\hline Spray angle & $30,60,80,90^{\circ}$ \\
\hline Injection pressure & $1,000,1500,2,000 \mathrm{bar}$ \\
\hline Working Fluid & Water \\
\hline
\end{tabular}

(1) Spray distance

The test method is as follows: First, the spray angle was fixed in 90 degree, and the injection pressure in 1,000 bar, the transfer velocity for a nozzle in $240 \mathrm{~mm} / \mathrm{min}$. Second, the distance between a nozzle and a specimen alters from $10 \mathrm{~mm}$ to $90 \mathrm{~mm}$ in $10 \mathrm{~mm}$ intervals. 


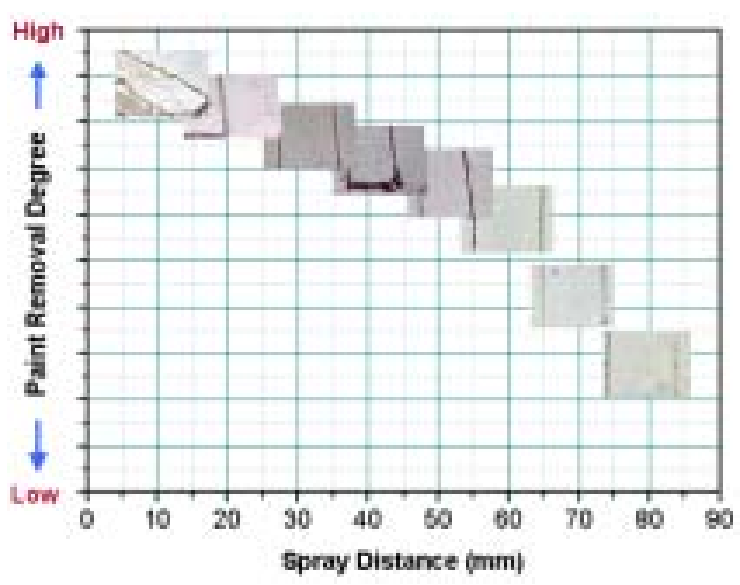

distance

Figure 8. Result by variation of spray

The qualitative test result is shown in Figure 8. At the distance range of $10 \sim 20 \mathrm{~mm}$, there is the damage to take off the asphalt as well as road markings, on the other hand, at $70 \sim 80 \mathrm{~mm}$, the road markings was not removed perfectly. In conclusion, it can be realized that the optimal spray distance in current condition is at $40 \sim 60 \mathrm{~mm}$

\section{(2) Spray angle}

The test method is as follows: First, the injection pressure was fixed to $1,000 \mathrm{bar}$, the transfer velocity for a nozzle in $240 \mathrm{~mm} / \mathrm{min}$. Second, the spray angle altered to the $30,60,80$ and 90 degree. As shown Figure 9, a nozzle is fixed at the device, and the incline angle of specimen on the bed is altered. Figure 9 shows the test apparatus for altering the spray angle.

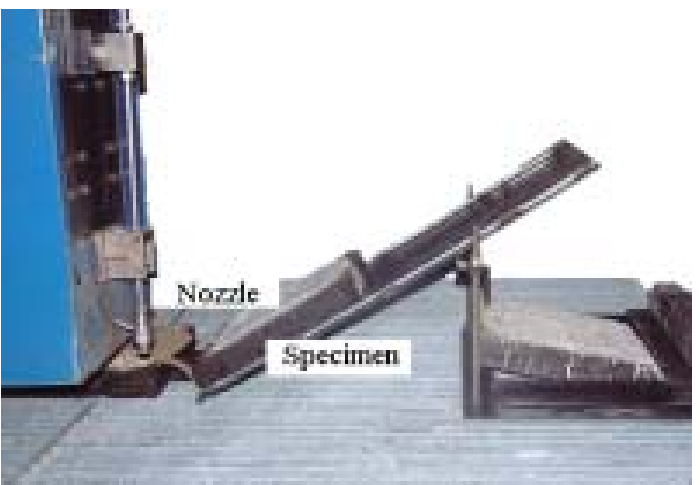

Figure 9. Test apparatus for the spray angle change

Figure 10 shows the experimental result in the case of different spray angle. Though the degree of removing is some qualitative, the spray angle at least should be 60 degree or more.

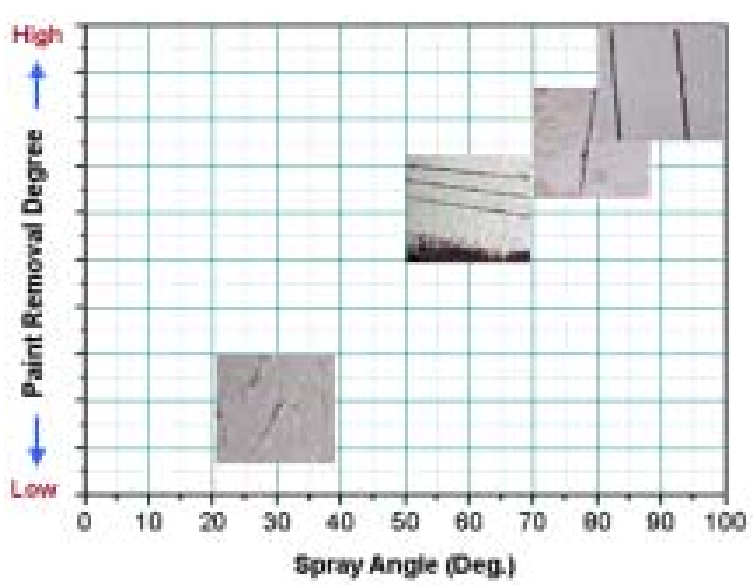

Figure 10. Result by variation of spray angle

(3) Injection pressure

The test method is as follows: First, a 1hole nozzle was made to reciprocate by using a rotational link and a servo motor while transferring in width direction simultaneously. Second, the spray distance was fixed to $20 \mathrm{~mm}$, the spray angle in 90 degree, the transfer velocity for a nozzle at $240 \mathrm{~mm} / \mathrm{min}$, the rotation speed of rotational link mechanism with $500 \mathrm{rpm}$, and injection pressure altered to 1000, 1500, and 2000 bar.

Figure 11 shows the rotational link mechanism.

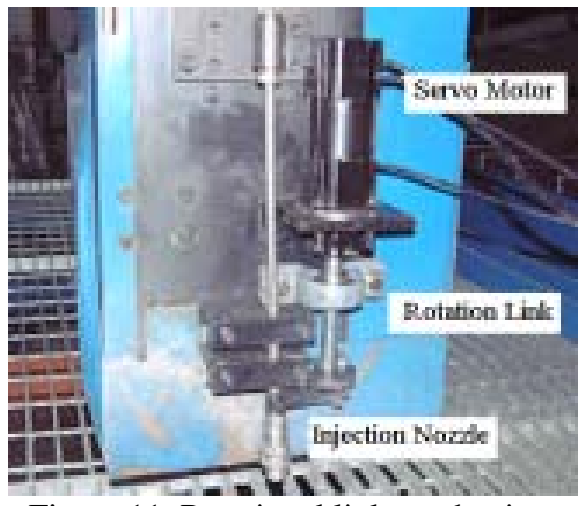

Figure 11. Rotational link mechanism

Figure 12 shows the experimental result in the case of different injection pressure. When water was injected with the pressure of 1,000 and 1,500 bar, the paint was not removed perfectly. It can be realized that the injection time is not sufficient but short due to quick reciprocating velocity. On the other hand, in 2,000 bar, the paint and even the asphalt of 1 2mm thickness were removed. In this condition, it is seemed that the injection pressure of 1700 1800 bar will be optimal. 


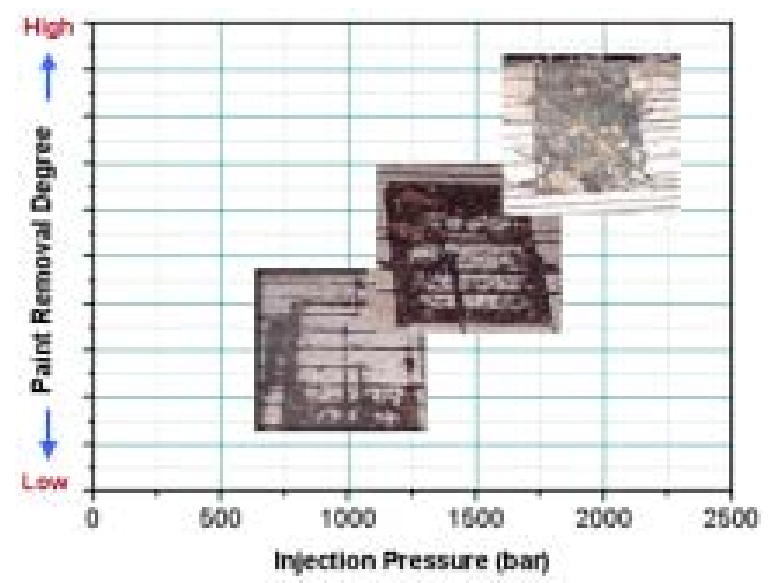

Figure 12. Result by variation of injection pressure

\section{Conclusion}

In this paper, for the development of the fast, safe, automatic and environmentally safe way to remove the road markings without damaging the surface by using water-jet, first of all, various analyses on the current shaving type removing method and work process through a field research were carried out. And, in the basis of these results, the whole system including each component have been organized and designed. Also, in order to examine the basic performance of manufactured equipment and to obtain basic data for the optimal spray condition, the basic experiment has been accomplished. In the future, after more detailed designs and system manufacturing, the performance on each components and the whole system will be evaluated, and the economic efficiency and marketability will be also analyzed.

\section{REFERENCES}

[1] SUGINO MACHINE LTd. CAT, 'Water Tools \& Accessories,' NO. U4201NE, pp. 24 25, 2003

[2] http://www.jetedge.com

[3] Road Traffic Act, Ministry of Government Administration and Home Affairs, 2003

[4] Standard specifications of Korea Highway Corporation, Ministry Construction \& Transportation, 1996

[5] Hydraulic \& Pneumatic Manual, Japan Hydraulic \& Pneumatic Society, pp. 359 363, 1989

[6] Hydraulic Control Systems, John Wiley \& Sons, Inc., pp 174 270 